\title{
Static and Dynamic Experiment Evaluations of a Displacement Differential Self-Induced Magnetorheological Damper
}

\author{
Guoliang Hu, ${ }^{1,2}$ Wei Zhou, ${ }^{1}$ Mingke Liao, ${ }^{1}$ and Weihua $\mathrm{Li}^{2}$ \\ ${ }^{1}$ School of Mechatronic Engineering, East China Jiaotong University, Nanchang, Jiangxi 330013, China \\ ${ }^{2}$ School of Mechanical, Materials and Mechatronic Engineering, University of Wollongong, Wollongong, NSW 2522, Australia \\ Correspondence should be addressed to Guoliang Hu; glhu2006@163.com
}

Received 17 December 2014; Accepted 26 February 2015

Academic Editor: Didier Rémond

Copyright (c) 2015 Guoliang Hu et al. This is an open access article distributed under the Creative Commons Attribution License, which permits unrestricted use, distribution, and reproduction in any medium, provided the original work is properly cited.

\begin{abstract}
This paper presents the development of a novel magnetorheological damper (MRD) which has a self-induced ability. In this study, a linear variable differential sensor (LVDS) based on the electromagnetic induction mechanism was integrated with a conventional MRD. The structure of the displacement differential self-induced magnetorheological damper (DDSMRD) was developed, and the theory of displacement differential self-induced performance was deduced. The static experiments of the DDSMRD under different displacement positions were carried out by applying sine excitation signals to the excitation coils, and the experimental results show that the self-induced voltage is proportional to the damper piston displacement. Meanwhile, the dynamic experiments were also carried out using the fatigue test machine to investigate the change of the self-induced voltage under the typical direct current inputs and the different piston rod displacements; the experimental results also show that the self-induced voltage is proportional to the damper piston displacements. Additionally, the dynamic mechanical performance of the DDSMRD was evaluated. The theory deduction and the experimental results indicate that the proposed DDSMRD has the ability of the integrated displacement sensor in addition to the output controllable damping force.
\end{abstract}

\section{Introduction}

In the past decades, various vibration control systems have been developed and applied in various industry fields; typically, they can be classified as passive, active, and semiactive vibration control systems. The passive vibration control systems, consisting of springs and conventional shock absorbers, can provide design simplicity, but they cannot provide effective vibration isolation for broadband excitations due to their limited tuned frequency. The active vibration control systems are capable of providing vibration control over large bandwidth disturbances through application of active forces. However, for practical large structures, they usually do demand large power sources to induce the required active forces, which may also destabilize the system if not properly designed. On the contrary, the semiactive vibration control systems can provide both the simplicity and reliability of passive systems while maintaining the adaptability of active vibration control systems without requiring large power inputs. In the semiactive control systems, the stiffness and damping properties of the passive devices can be changed through an appropriate control algorithm and thus they can provide the desirable performance with no need of large power sources and expensive hardware [1-4].

In recent years, semiactive control devices have received significant attentions. Among them, magnetorheological damper (MRD) is a typical semiactive vibration control device that uses MR fluids to produce controllable damping forces. It potentially offers highly reliable operation and can be viewed as fail-safe in that it becomes passive damper if the control hardware is out of work [5-7]. Due to its fast adjustable response, long range of controllable damping force, simple structure, long durability, and low energy consumption, MRD has been widely used in the semiactive vibration control systems and vibration reduction systems such as automotives $[8,9]$, building and bridge vibration attenuation $[10-$ $12]$, and other semiactive vibration isolation systems $[13,14]$. To effectively reduce the influence of vibration force on these 
structures, the MRD semiactive vibration control system chooses a closed-loop control to these structures through the changing of controllable damping force under a direct current generated by the controller system according to the signal of force sensor and the response of displacement sensor.

Taking the semiactive vehicle suspension systems based on MR dampers as an example, there are three kinds of configurations of the dynamic response sensors and MR dampers including the following: (a) the dynamic response is accessed with two accelerometers; (b) the dynamic response is accessed with one relative velocity sensor; and (c) the dynamic response is accessed with one relative displacement sensor [15-17]. In any case, the dynamic response sensors are necessary and separately aligned with the MR dampers, which make the system complicated, the installation space occupied, the cost increased, and the system reliability decreased.

In order to simplify the structure of the MRD semiactive vibration control system, reduce cost of daily maintenance, improve the reliability of operation, and decrease the installation spaces, an innovative approach integrating a self-induced structure into MRD has been developed by a number of research groups. The integration of self-induced function with MRD could take place the traditional MRD with an extra displacement sensor, which can be used in the semi-active vibration control system due to its compact structure and high reliability.

Nehl et al. did a pioneering work in developing an integrated relative velocity sensor which integrates into a liquid damper. The integrated relative velocity is working under the static magnetic field and output self-induced voltages dependent on velocity. The integrated plan above cannot be used into MR damper because the self-induced static magnetic field would have an effect on the performance of damper seriously $[18,19]$. Later on, Wang and his coworkers proposed a novel modeling of integrated displacement selfsensing MR damper $[20,21]$. Although the modeling was able to generate self-sensing voltages, the magnetic circuit is unstable by passing through the upper lid, and the reluctance of whole circuit is variable that makes the self-sensing voltages have theoretical deviation with true value. Additionally, the integration could degrade the performance of both sensing and damping capabilities. In their study, the Pareto optimization method was used to handle the tradeoff between the damping force and sensing performance [22]. Wang and Bai also proposed an MR damper with an integrated selfpowered displacement sensor based on frequency division multiplexing of the exciting coil and function multiplexing of the pick-up coil and induction coil. The developed MR damper not only possessed a large range of controllable damping force and reasonable self-sensing property but also possessed the capacity to harvest the mechanical to electrical energy [23].

Chen and Liao designed and fabricated a self-powered and self-sensing MR damper which integrated a power part and sensor part $[24,25]$. However, the complex structure and difficult installation make it hard to find practical applications. Lam et al. developed an MR damper with dualsensing capability by integrating a piezoelectric force sensor and a displacement transducer with a conventional actuationonly MR damper. The experimental results showed that the MR damper with embedded force and displacement sensors had advantages in fulfilling real-time closed-loop feedback control applications for mitigating structural vibrations in a reliable and simple manner [26]. Wang et al. presented a new self-powered and sensing semiactive control system based on MR damper. The numerical simulation results showed that the two self-powered control strategy could get close performance with its corresponding semiactive control with external power supply [27]. Choi and Wereley studied the feasibility and effectiveness of a self-powered MR damper using a spring-mass electromagnetic induction device [28]. Sapiński proposed a semiactive vibration control system comprising the EMI prototype and the damper RD 1005-3 and employed an electromagnetic transduction mechanism to extract energy from vibrations. The experiments demonstrated that the proposed system was able to supply power to the MR damper and the EMI acted as a "velocity-sign" sensor [29]. Our group proposed a self-sensing MR damper whose performance was evaluated with simulation analysis [30]. However, the accuracy of the self-sensing ability needs to be improved.

In this study, we extended our work in developing a displacement differential self-induced MR damper (DDSMRD) by integrating a linear variable differential sensor (LVDS) into a traditional MRD for realizing a new functional MR damper that has the self-induced ability. This paper is organized as follows. Firstly, the structure design and self-induced performance analysis of the proposed DDSMRD were presented. Then, the experimental tests of the static and dynamic self-induced performance were carried out and discussed in detail; also the dynamic mechanical performance was experimentally evaluated. Main findings were summarized in the conclusion.

\section{Structure and Self-Induced Performance Analysis of DDSMRD}

2.1. Structure Design and Consideration of DDSMRD. Figure 1 shows the schematic diagram of the proposed DDSMRD, Figure 2 shows the prototyping of the DDSMRD, and Table 1 gives the detailed specifications of the DDSMRD. The proposed DDSMRD mainly consists of a composite piston head which wound excitation coils, a winding cylinder which wound differential self-induced coils, and an outer cover. Specifically, the coils wound on the composite piston head act as an excitation coil and provide magnetic fields to both LVDS and MR fluids simultaneously, while differential self-induced coils wound on the winding cylinder generate electromotive forces and output self-induced voltages. The composite piston head can input alternating currents in different frequencies and direct currents at the same time. The magnetic field generated by the alternating current enables differential selfinduced coils to produce self-induced voltages, while the magnetic field generated by the direct current magnetizes the MRF in the resistance gap. The input voltage is through 


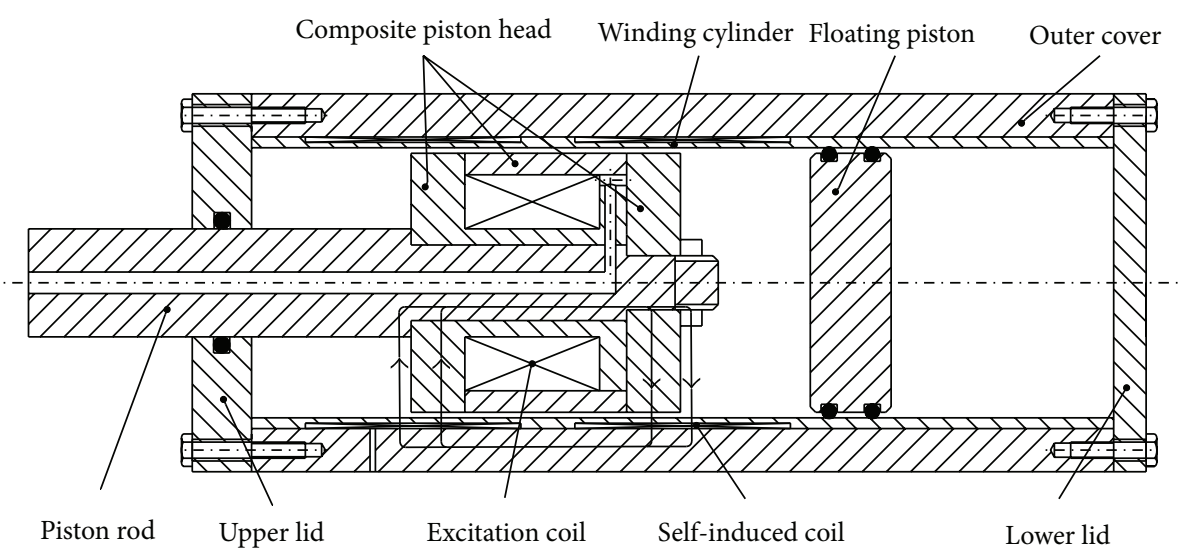

FIGURE 1: Schematic diagram of the proposed DDSMRD.

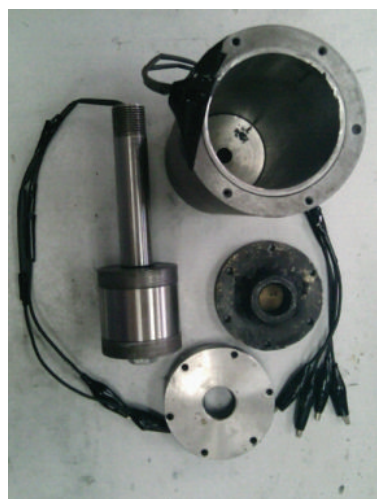

(a)

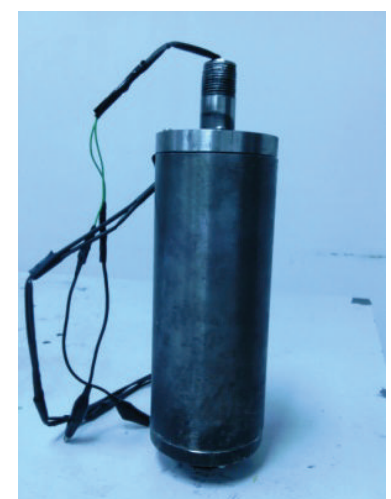

(b)

FIgURE 2: Prototyping of the proposed DDSMRD.

TABLE 1: Basic values of the structure parameters for the DDSMRD.

\begin{tabular}{lcc}
\hline Parameter & Symbol & Values \\
\hline Piston rod diameter & $d$ & $20 \mathrm{~mm}$ \\
Piston head diameter & $D$ & $48 \mathrm{~mm}$ \\
Effective length & $l$ & $20 \mathrm{~mm}$ \\
Gap thickness & $h$ & $1 \mathrm{~mm}$ \\
Winding cylinder inner diameter & $D_{w}$ & $50 \mathrm{~mm}$ \\
Outer cover outside diameter & $D_{o}$ & $70 \mathrm{~mm}$ \\
Piston effective displacement & $l_{p}$ & $40 \mathrm{~mm}$ \\
Winding cylinder thickness & $t$ & $2 \mathrm{~mm}$ \\
Outer cover thickness & $w$ & $10 \mathrm{~mm}$ \\
Excitation coil turns & $N$ & 950 \\
Self-induced coil turns & $N_{1}$ & 160 \\
Self-induced coil turns & $N_{2}$ & 160 \\
\hline
\end{tabular}

the hollow on the piston rod, and the output self-induced voltage is through the hollow on the outer cover.

In this design, a nonmagnetic metal (stainless steel) was used to fabricate the piston rod, the winding cylinder, shade ring of the composite piston head, the upper lid, and the lower lid to avoid the magnetic circuit passing through, while a magnetic metal (10\# steel) was used to fabricate the outer cover, the winding holder, and the shade board of the composite piston head to generate a closed-loop working magnetic circuit. The output MRD damping force generally consists of two parts: the shear damping force and the valve damping forces, which are generated by shearing MR fluids in the resistance gap by the pressure drops of two chambers, respectively.

2.2. Analysis of Self-Induced Performances of DDSMRD. The key technology for self-induced ability of the proposed DDSMRD is an integrated linear variable differential sensor (LVDS) method based on the electromagnetic induction and carrier superposition. To save the installation space and maintain functions, the DDSMRD structure reusing the excitation coil is wound on the composite piston head as the exciting coil for the LVDS, the differential self-induced coils are wound on the winding cylinder which is located in the inner parts of the outer cover, and the alternating current (AC) is input to the excitation coil to generate alternating magnetic field for ILVDS. The structure of the ILVDS integrated in the DDSMRD is shown in Figure 3. The DDSMRD has the excitation coil wound on the composite piston head (yellow color) and the two differential self-induced coils for 


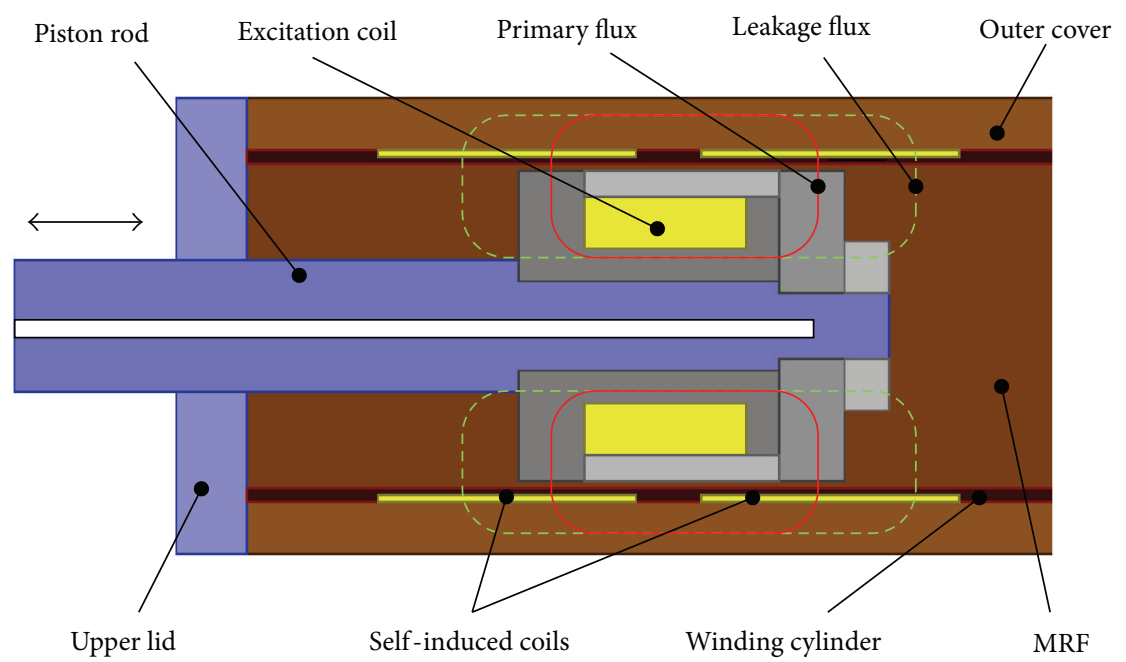

Figure 3: Principle diagram of DDSMRD.

LVDS wound on winding cylinder; the primary flux of selfinduced magnetic path is shown in curve as red color and the leakage flux of self-induced magnetic path is shown in curve as green color. The magnetic circuit of LVDS is the same as the magnetic circuit of MRD damping force. To build up the DDSMRD which integrated LVDS, the self-induced magnetic circuit is ensured not to disturb the damping force magnetic circuit, and the leakage flux should be as small as possible.

The excitation coil in the composite piston head was applied alternating current (AC) and direct current (DC) simultaneously. The magnetic field generated by the DC signal magnetizes MRF of resistance gap. So the DC input value of the piston head can be changed to obtain different damping force.

The circuit diagram of differential self-induced performance integrated LVDS technology is shown in Figure 4. The magnetic field generated by the AC input does not much affect damping force, and the self-induced coils in the winding cylinder induce a signal in which its amplitude is proportional to the turn of coils in the magnetic field and its frequency is the same as the excitation signal. As shown in Figure 4, two differential self-induced coils are wound on the winding cylinder of DDSMRD, and the amplitude of measured signal is the difference between the amplitudes of two self-induced coils according to the differential principle.

In Figure $4, \dot{U}$ is the voltage of AC excitation input, $\dot{U}_{1}$ is the output differential self-induced voltage, $L_{1}$ is the selfinductance of excitation coils, $L_{2}$ and $L_{3}$ are self-inductance of self-induced coils connected in the way of differential, respectively. $N$ is the turn of excitation coils and $N_{1}$ and $N_{2}$ are turns of two differential self-induced coils, respectively. $R_{1}$ is the resistance of excitation coils and $R_{2}$ and $R_{3}$ are the resistance of self-induced coils, respectively.

The alternating current in excitation coils is given by

$$
\dot{I}=\frac{\dot{U}}{Z}=\frac{\dot{U}}{R_{1}+j \omega L_{1}} .
$$

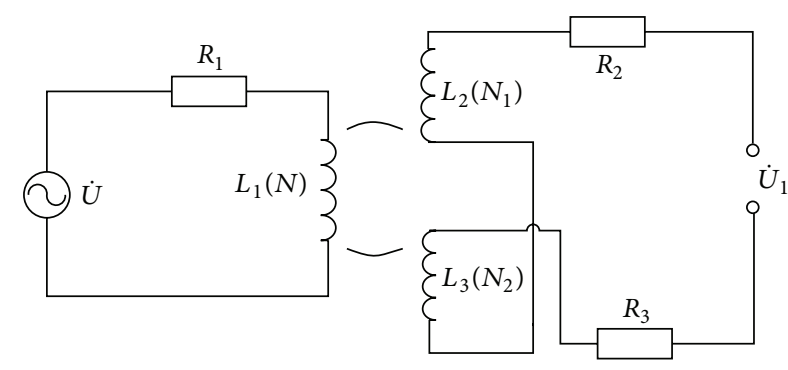

FIGURE 4: Principle of differential self-induced performance of DDSMRD.

The magnetic flux in differential self-induced coils is

$$
\phi=\frac{N \dot{I}}{R} .
$$

The reluctance of magnetic circuit is

$$
R=\sum \frac{l_{i}}{\mu_{i} S_{i}}+\frac{2 h}{\mu_{0} S}
$$

where $l_{i}$ is the conductor length of each section in the magnetic circuit, $\mu_{i}$ is the permeability of each section, $S_{i}$ is the cross-sectional area of each section, $\mu_{0}$ is the permeability of vacuum, $h$ is the thickness of air gap, and $S$ is the area of the air cross-sectional area.

The reluctance of magnetic circuit $R$ in (3) consists of two parts: the first term is the sum of the reluctance of the winding holder and the shade board of the composite piston head and the reluctance of the outer cover in the primary magnetic circuit; the second term is the reluctance of air gap among the composite piston head and outer cover. As the value of $\mu_{i}$ is much greater than that of $\mu_{0}$, the reluctance of air gap is the major part of the reluctance of magnetic circuit.

Ignoring the change of magnetic resistance caused by the piston movement and assuming the resistance of magnetic 
circuit is constant, it can be seen that the magnetic flux is proportional to the excitation voltage from (1) and (2). Setting the sine excitation in the excitation coils is $u(t)=$ $U_{m} \sin (2 \pi f t)$, here $f$ is the frequency of sine excitation, and $u_{m}$ is the amplitude voltage of the sine excitation.

The magnetic flux in the self-induced coils is given by

$$
\phi_{1}(t)=\phi_{2}(t)=\phi(t)=\phi_{m} \sin (2 \pi f t) .
$$

$\phi_{m}$ is the peak value of the primary magnetic flux in the magnetic circuit, and it is given by

$$
\phi_{m}=k U_{m}
$$

where $k$ is a constant coefficient.

The flux linkage of the two self-induced coils in the primary magnetic circuit is defined as

$$
\begin{aligned}
& \psi_{1}(t)=\phi_{1}(t) N_{1}(t)=k U_{m} \sin (2 \pi f t) N_{1}(t) \\
& \psi_{2}(t)=\phi_{2}(t) N_{2}(t)=k U_{m} \sin (2 \pi f t) N_{2}(t),
\end{aligned}
$$

where $N_{1}(t)$ and $N_{2}(t)$ are turns of self-induced coils in the main magnetic circuit, respectively. They are given by

$$
\begin{aligned}
& N_{1}(t)=k_{1} x_{1}(t) \\
& N_{2}(t)=k_{2} x_{2}(t),
\end{aligned}
$$

where $k_{1}$ and $k_{2}$ are denoted as the turn of two self-induced coils per distance along the winding cylinder and the two constants of $k_{1}=k_{2}$. The position in the middle of two selfinduced coils is set as the zero position, the piston moving upward is positive, and the displacements of the piston relative to the coils are $x_{1}(t)$ and $x_{2}(t)$, respectively. They are given by

$$
x_{1}(t)=-x_{2}(t)=\Delta x(t)
$$

The instantaneous value of self-induced voltage in the self-induced coils is

$$
\begin{aligned}
e_{2}(t)=\frac{d \psi_{1}(t)}{d t}=k k_{1} U_{m}[ & 2 \pi f \Delta x(t) \cos (2 \pi f t) \\
& \left.+\frac{d \Delta x(t)}{d t} \sin (2 \pi f t)\right] \\
e_{3}(t)=\frac{d \psi_{2}(t)}{d t}=-k k_{2} U_{m} & {[2 \pi f \Delta x(t) \cos (2 \pi f t)} \\
& \left.+\frac{d \Delta x(t)}{d t} \sin (2 \pi f t)\right] .
\end{aligned}
$$

According to the differential self-induced principle, the instantaneous value of self-induced voltage is deduced as

$$
\begin{aligned}
e_{1}(t)=e_{2}(t)-e_{3}(t)=2 k k_{1} U_{m}[ & 2 \pi f \Delta x(t) \cos (2 \pi f t) \\
& \left.+\frac{d \Delta x(t)}{d t} \sin (2 \pi f t)\right] .
\end{aligned}
$$

Due to the low damper movement speed and high frequency of excitation signal, the right part in (10) can be considered as

$$
2 \pi f \Delta x(t) \cos (2 \pi f t) \gg \frac{d \Delta x(t)}{d t} \sin (2 \pi f t) .
$$

So the instantaneous value of the self-induced voltage in (10) can be deduced as

$$
e_{1}(t) \approx 4 \pi f k k_{1} U_{m} \Delta x(t) \cos (2 \pi f t) .
$$

Finally, the effective value of self-induced voltage can be considered as

$$
U_{1}=4 \pi f k k_{1} U_{m} \Delta x(t) .
$$

As $k, k_{1}, f$, and $U_{m}$ are constants, the self-induced voltage $U_{1}$ is proportional to the relative displacement of the damper piston. That is to say, the principle of the integrated LVDS is ensured.

2.3. Magnetic Properties of MR Fluid and Steel Used in the Proposed DDSMRD. The MR fluid provided by the Chongqing Instrument Material Research Institute in China was used in the following static and dynamic experiments. Its field dependent properties are shown in Figure 5.

Figure 6 shows the relationship between the magnetic flux density and the magnetic field intensity of the 10\# steel material used in the outer cover, the winding holder, and the shade board of the composite piston head, respectively.

\section{Analysis of Self-Induced Performance of DDSMRD under Static Experiments}

3.1. Development of Self-Induced Signal Acquisition System. In order to acquire the self-induced signal of DDSMRD, a signal acquisition system shown in Figure 7 was developed. The system mainly consists of function signal generator, the proposed DDSMRD, signal acquisition card, and LabVIEW interface of signal acquisition. The function signal generator was used to provide sine excitation signal to the excitation coil on the piston head. The signal acquisition card was adopted to acquire the self-induced voltage signal that is proportional to the damper displacement. The LabVIEW interface of signal acquisition was applied to display and analyze the displacement signal.

In the static experiments, the function signal generator was set as sine wave with amplitude of $2 \mathrm{~V}$ and frequency of $1 \mathrm{kHz}$. The analog input channel was set as AI0, the input mode was set as differential input, the sampling frequency was $20000 \mathrm{~Hz}$, and the sampling number of single channels was 100 in the signal acquisition system. The filter type was band pass with two orders. The damper piston position of $0 \mathrm{~mm}, \pm 5 \mathrm{~mm}$, and $\pm 10 \mathrm{~mm}$ was calibrated, respectively.

3.2. Self-Induced Voltage under $\pm 5 \mathrm{~mm}$ Displacement. In the first static experiment, the zero position in the middle of the two self-induced coils was set as position 2 and the upward $+5 \mathrm{~mm}$ was denoted as position 1, while the downward 


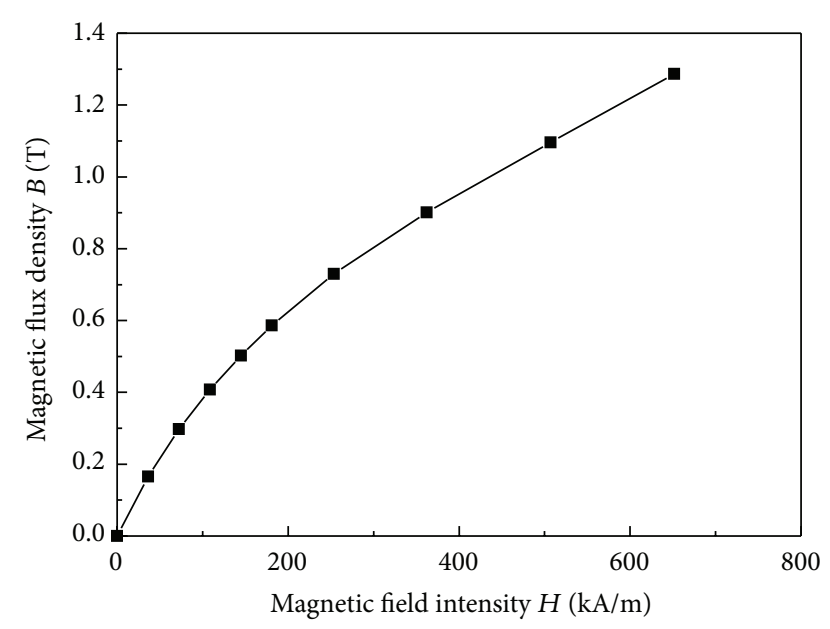

Figure 5: The variation of the magnetic flux density $B$ and the magnetic field intensity $H$.

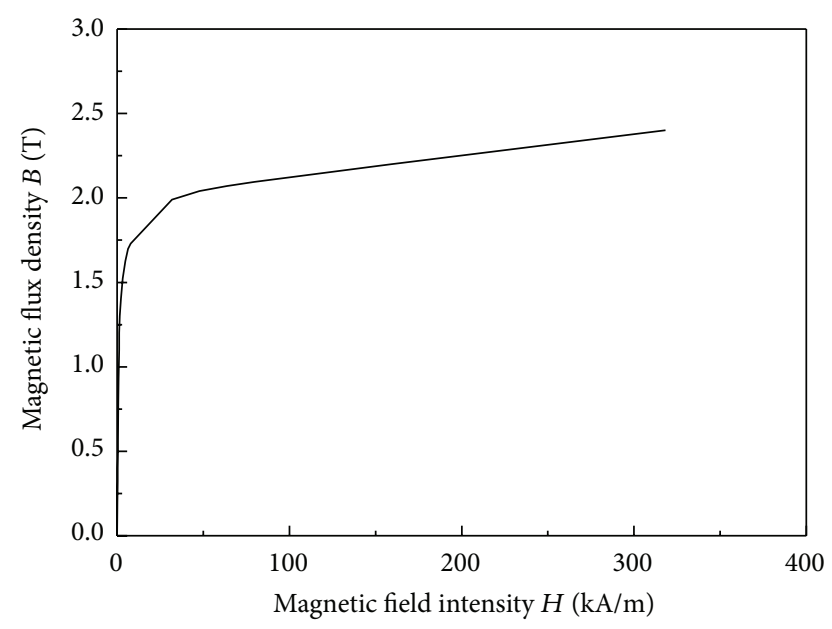

FIgURE 6: $B$ - $H$ curve of 10\# steel material.
Signal acquisition card

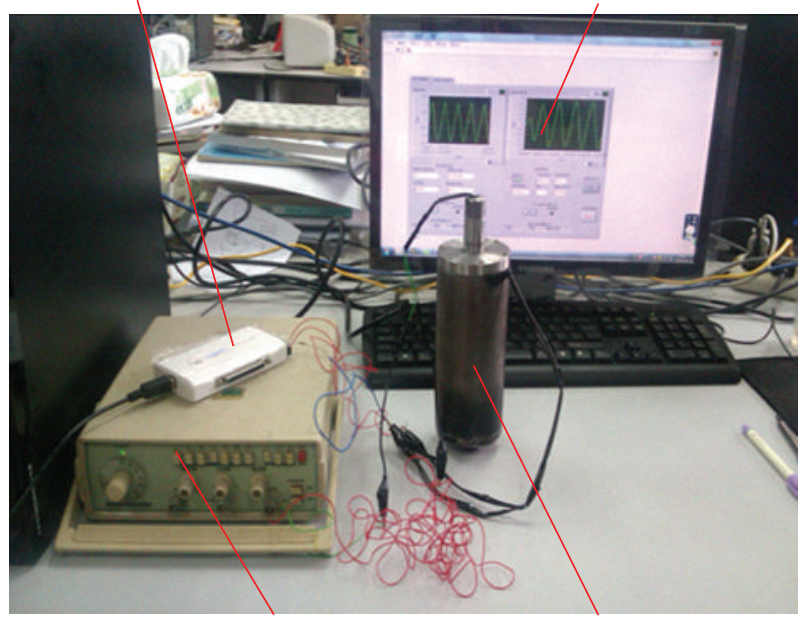

Function signal generator
DDSMRD
FIGURE 7: Signal acquisition system of self-induced voltage.
$-5 \mathrm{~mm}$ was denoted as position 3. The initial position of damper piston was kept in position 1, and the filter data was saved. When the damper piston was moved from position 1 to position 2, the change of the self-induced voltage was obtained which is shown in Figure 8. At the same time, the change of the self-induced voltage was obtained too when the damper piston was moved from position 2 to position 3 which is shown in Figure 9.

It can be seen that the positive amplitude of the selfinduced voltage equaled the negative amplitude of the selfinduced voltage after the filtering. The reason is that the DC bias signal of acquisition card was filtered out with band pass filter effectively. The self-induced voltage of position 1 is about $0.035 \mathrm{~V}$, the self-induced voltage of position 2 is about $0.005 \mathrm{~V}$, and the self-induced voltage of position 3 is about $0.035 \mathrm{~V}$ from both figures. The self-induced voltage from position 1 to position 2 was decreased while it increased from position 2 to position 3 . However, the self-induced voltage of position 2 is not zero strictly due to the coiling accuracy and the calibration error of zero position.

3.3. Self-Induced Voltage under $\pm 10 \mathrm{~mm}$ Displacement. In the second static experiment, the zero position was still set as position 2 , while the upward $+10 \mathrm{~mm}$ was denoted as position 1 and the downward $-10 \mathrm{~mm}$ was denoted as position 3 . Figures 10 and 11 showed the change of the self-induced voltage from position 1 to position 2 and from position 2 to position 3 , respectively.

Observing Figures 10 and 11, it can be seen that the selfinduced voltage of position 1 is about $0.07 \mathrm{~V}$, the self-induced voltage of position 2 is about $0.005 \mathrm{~V}$, and the self-induced voltage of position 3 is about $0.07 \mathrm{~V}$. The same trend is that the self-induced voltage from position 1 to position 2 was decreased while it increased from position 2 to position 3 . The self-induced voltage of position 1 equaled that of position 3 , and it was twice that of the first static experiment. So, it can be deduced that the change of the self-induced voltage is proportional to the damper displacement.

\section{Analysis of Self-Induced Performance of DDSMR under Dynamic Experiments}

4.1. Test Rig of Dynamic Displacement Self-Induced Performance. Figure 12 shows the dynamic experimental test rig of the proposed DDSMRD. The direct current was supported by the DC power supply, and the alternating current was supported by the function signal generator. The signal acquisition card was used to collect the displacement selfinduced voltage signal of the damper and the self-induced voltage signal was received by the LabVIEW programming. The fatigue test machine was used to control the damper movement and monitor the change of force and displacement in real time, and the relationship between the damping force and damper displacement could be obtained by the test machine controller. The power of the fatigue test machine was supported by the power unit.

4.2. Experimental Analysis of Dynamic Displacement SelfInduced Performance. Figure 13 shows the self-induced 


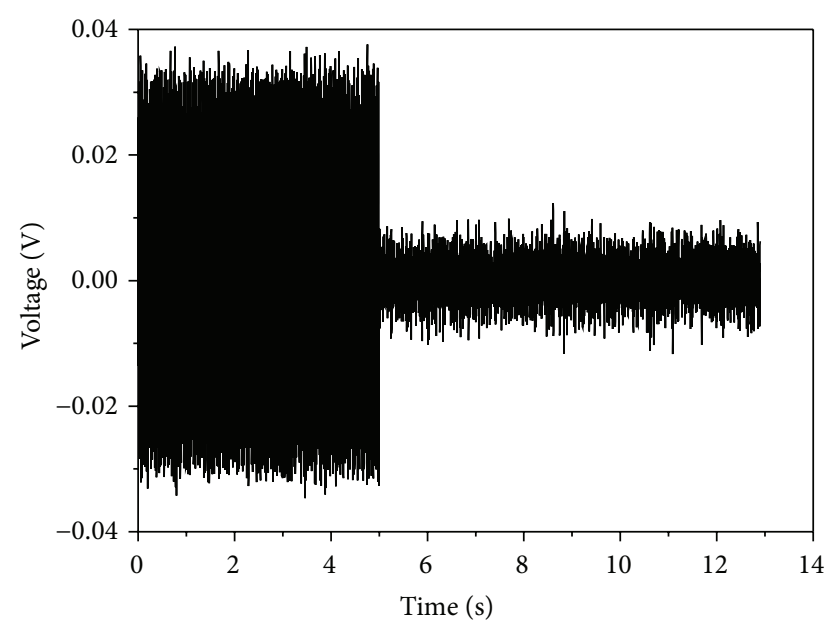

FIGURE 8: Change of self-induced voltage from position 1 to position 2.

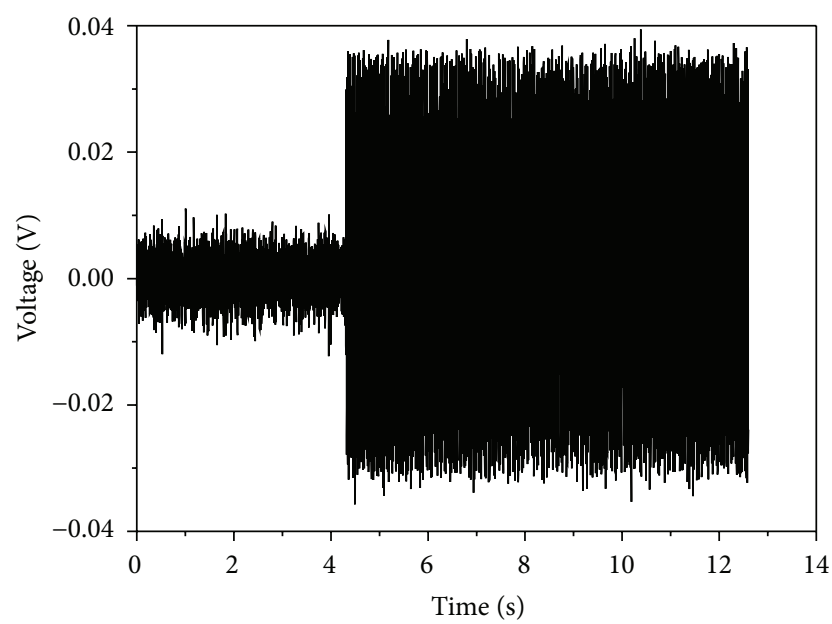

FIGURE 9: Change of self-induced voltage from position 2 to position 3.

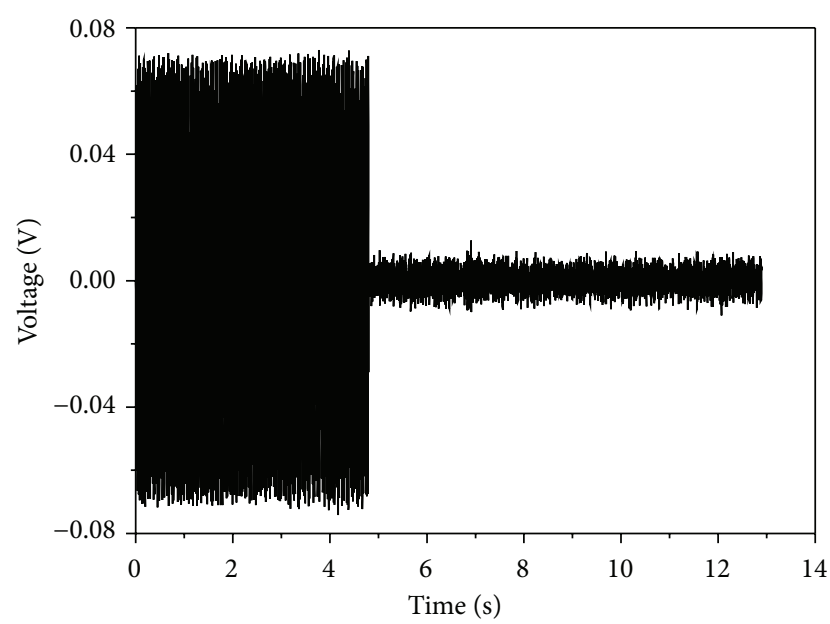

FIgURE 10: Change of self-induced voltage from position 1 to position 2.

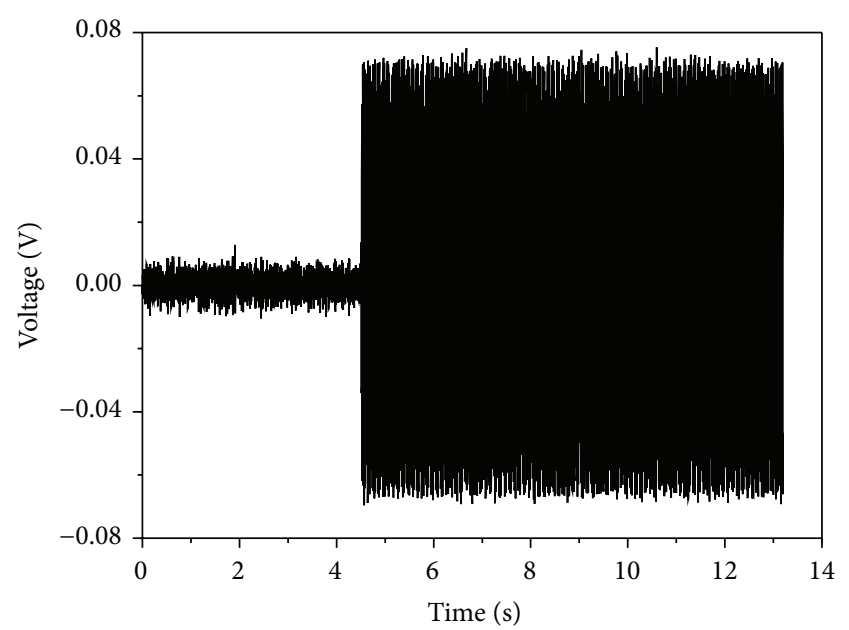

FIGURE 11: Change of self-induced voltage from position 2 to position 3 .

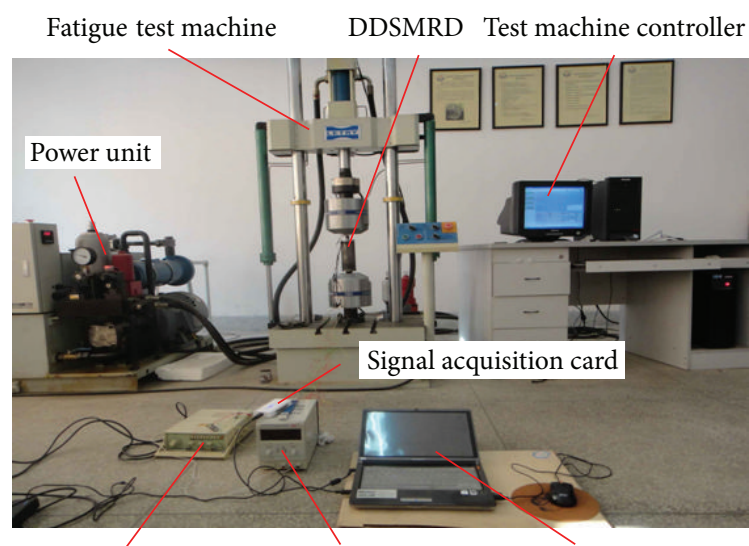

Function signal generator DC power supply LabVIEW programming

FIGURE 12: Test rig of dynamic displacement self-induced performance.

voltage under different damper displacement input when the DC input for the excitation coil was set as $0.25 \mathrm{~A}$. Figure 14 shows the self-induced voltage under different damper displacement input when the DC input for the excitation coil was set as $0.5 \mathrm{~A}$. The testing frequency was $1 \mathrm{~Hz}$ and the damper displacement was set as $2 \mathrm{~mm}, 3 \mathrm{~mm}$, $4 \mathrm{~mm}, 5 \mathrm{~mm}$, and $6 \mathrm{~mm}$, respectively. The AC voltage is $6.0 \mathrm{~V}$ and the frequency is $1 \mathrm{kHz}$. As shown in both figures, the self-induced voltage changed cyclically with the piston displacement, which is similar to the positive half cycle of sine wave and identifies with the movement of the piston head. As expected, the maximum self-induced voltage is increased with the increase of the damper displacement.

Figure 15 shows the relationship between the maximum self-induced voltage and piston displacement under two typical direct currents inputs. Observing the figure, the line slope between the maximum self-induced voltage and the piston displacement is the same under the DC input of $0.25 \mathrm{~A}$ and $0.5 \mathrm{~A}$, which means the maximum self-induced voltage 


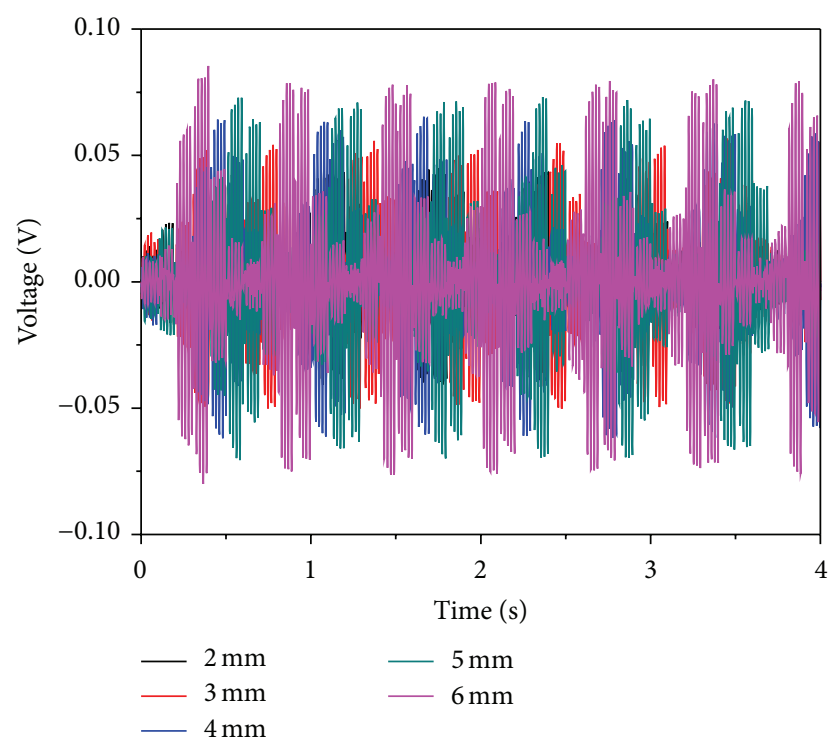

FIGURE 13: Self-induced voltage under different damper displacement input as the DC input was set as $0.25 \mathrm{~A}$.

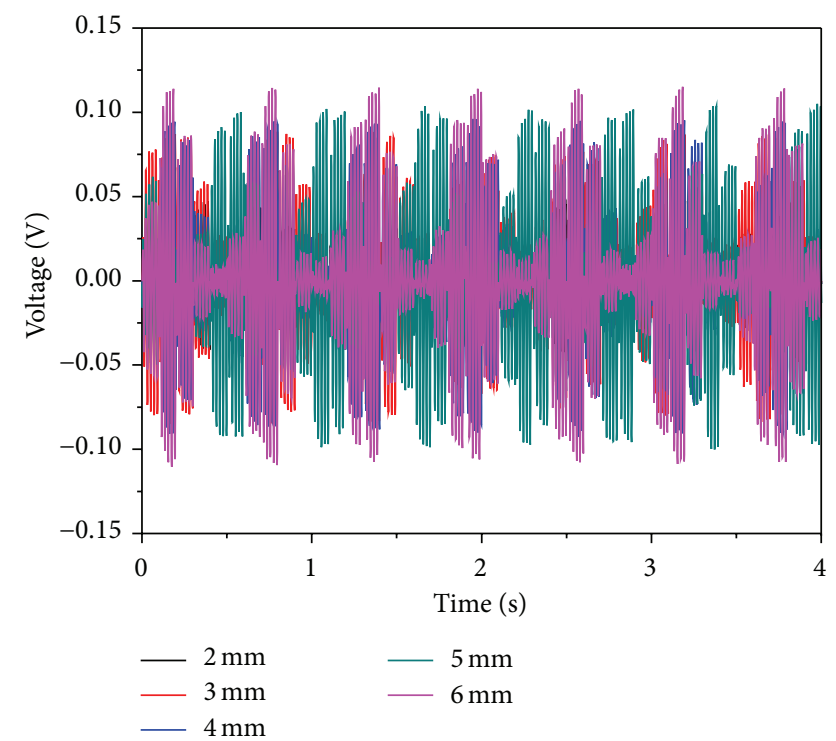

Figure 14: Self-induced voltage under different damper displacement input as the DC input was set as $0.5 \mathrm{~A}$.

is proportional to the damper displacement. However, the maximum self-induced voltage in the zero displacement is not zero under these two kinds of DC input. The reason is that the clamping position of the damper is not in the zero point strictly; it has a certain deviation.

\subsection{Experimental Analysis of Dynamic Mechanical Perfor-} mances. Figure 16 shows the relationship between the damping force and the piston displacement under different DC input when the displacement of fatigue test machine was set as $\pm 5 \mathrm{~mm}$. It can be seen that the maximum damping force of DDSMRD increases from $200 \mathrm{~N}$ of $0 \mathrm{~A}$ to $420 \mathrm{~N}$ of $0.75 \mathrm{~A}$

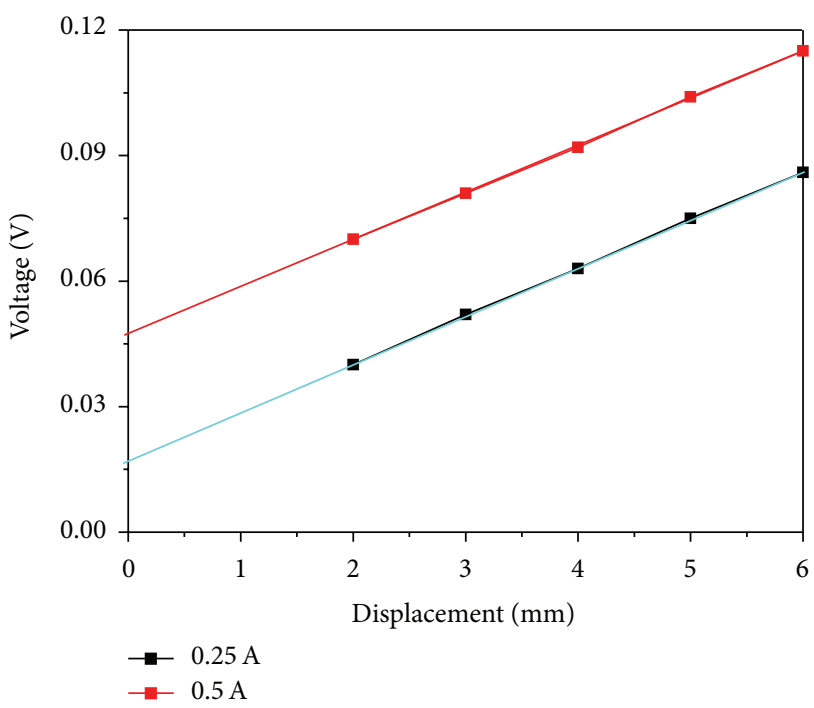

FIGURE 15: Self-induced voltage under different damper displacement.

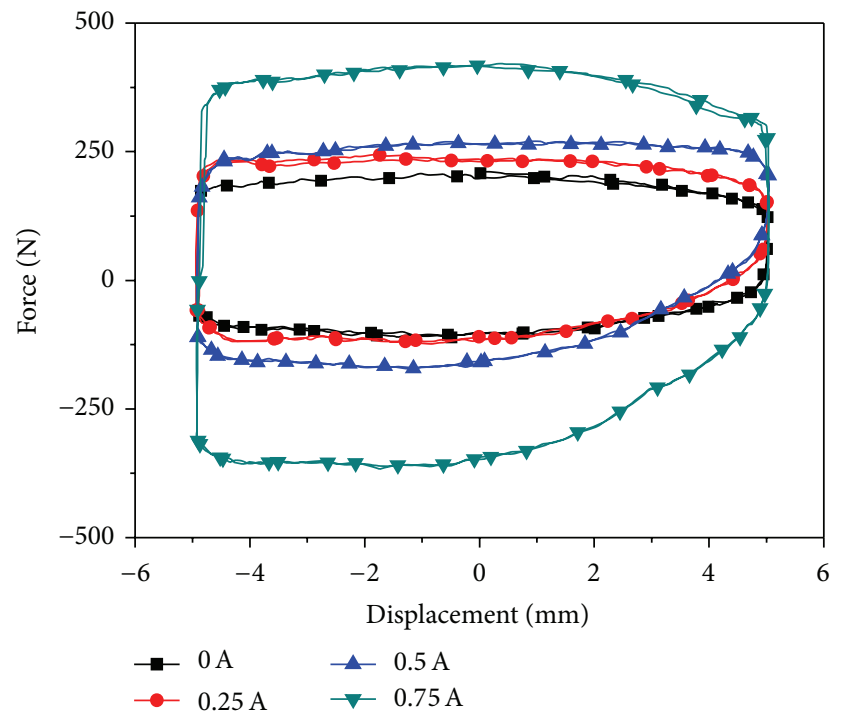

FIgURE 16: Diagram of experiment force-displacement under different direct current input.

as the DC current increases. So, the proposed DDSMRD not only can produce the self-induced voltage that is proportional to the damper displacement but also has the effect of damping force ability of conventional MRD. In addition, the size of damping force is not equal when damper piston head moves up and down at the same position due to the gravity of damper piston head and the seal of the end cover.

\section{Conclusion}

In this paper, a displacement differential self-induced magnetorheological damper (DDSMRD) based on the integrated linear variable differential sensor (LVDS) technology was 
developed. The major structure of the DDSMRD is the excitation coil wound on the piston head and two self-induced coils wound on the winding cylinder. In the proposed DDSMRD, the excitation coil was multiplexed by input direct current which magnetizes MRF in the resistance gap and $1 \mathrm{kHz}$ frequency carrier of alternating current for the LVDS.

The performance of the embedded sensor was evaluated through the static and dynamic experiments. In the static experiments, the self-induced voltage increased with the increase of the damper displacement, and the maximum selfinduced voltage is proportional to the damper displacement. In the dynamic experiments, the maximum self-induced voltage increased with the increase of the damper displacement too, and the change of self-induced voltage amplitude coincides with the movement of the piston basically. Additionally, the developed DDSMRD has a similar damping performance as conventional MR damper.

This research is expected to not only provide a new method to decrease the installation spaces and maintain spending of MR damper system, but also lead to potential applications of MR damper in industries, such as vehicles and bridges. Because of the proposed DDSMRD structure, displacement sensors outside the MR damper are likely not to be needed.

\section{Conflict of Interests}

The authors declare that there is no conflict of interests regarding the publication of this paper.

\section{Acknowledgments}

This research was financially supported by the National Natural Science Foundation of China (nos. 51475165, 51165005, and 11462004) and the Australian Research Council Discovery Project (no. 1501002636).

\section{References}

[1] G. W. Housner, L. A. Bergman, T. K. Caughey et al., "Structural control: past, present, and future," Journal of Engineering Mechanics, vol. 123, no. 9, pp. 897-971, 1997.

[2] N. Jalili, "A comparative study and analysis of semi-active vibration-control systems," Journal of Vibration and Acoustics, vol. 124, no. 4, pp. 593-605, 2002.

[3] B. F. Spencer Jr. and S. Nagarajaiah, "State of the art of structural control," Journal of Structural Engineering, vol. 129, no. 7, pp. 845-856, 2003.

[4] A. Hadadian, R. Sedaghati, and E. Esmailzadeh, "Design optimization of magnetorheological fluid valves using response surface method," Journal of Intelligent Material Systems and Structures, vol. 25, no. 11, pp. 1352-1371, 2013.

[5] A. Ashfak, A. Saheed, K. K. A. Rasheed et al., "Design, fabrication and evaluation of MR damper," International Journal of Aerospace and Mechanical Engineering, vol. 1, pp. 27-33, 2011.

[6] X. Zhu, X. J. Jing, and L. Cheng, "Magnetorheological fluid dampers: a review on structure design and analysis," Journal of Intelligent Material Systems and Structures, vol. 23, no. 8, pp. 839-873, 2012.
[7] B. Sapiński and M. Rosół, "MR damper performance for shock isolation," Journal of Theoretical and Applied Mechanics, vol. 45, pp. 133-145, 2007.

[8] S. Q. Abu-Ein, S. M. Fayyad, W. Momani, A. Al-Alawin, and M. Momani, "Experimental investigation of using MR fluids in automobiles suspension systems," Research Journal of Applied Sciences, Engineering and Technology, vol. 2, no. 2, pp. 159-163, 2010.

[9] S. H. Ha, M.-S. Seong, and S.-B. Choi, "Design and vibration control of military vehicle suspension system using magnetorheological damper and disc spring," Smart Materials and Structures, vol. 22, no. 6, Article ID 065006, 2013.

[10] H.-J. Jung, K.-M. Choi, B. F. Spencer Jr., and I.-W. Lee, "Application of some semi-active control algorithms to a smart baseisolated building employing MR dampers," Structural Control and Health Monitoring, vol. 13, no. 2-3, pp. 693-704, 2006.

[11] H. Laalej and Z. Q. Lang, "Numerical investigation of the effects of $\mathrm{mr}$ damper characteristic parameters on vibration isolation of SDOF systems under harmonic excitations," Journal of Intelligent Material Systems and Structures, vol. 21, no. 5, pp. 483-501, 2010.

[12] A. Rodríguez, F. Pozo, A. Bahar, L. Acho, Y. Vidal, and J. Rodellar, "Force-derivative feedback semi-active control of base-isolated buildings using large-scale MR fluid dampers," Structural Control and Health Monitoring, vol. 19, no. 1, pp. 120145, 2012.

[13] M. Mao, W. Hu, Y.-T. Choi, and N. M. Wereley, "A magnetorheological damper with bifold valves for shock and vibration mitigation," Journal of Intelligent Material Systems and Structures, vol. 18, no. 12, pp. 1227-1232, 2007.

[14] Y.-T. Choi and N. M. Wereley, "Shock isolation systems using magnetorheological dampers," Journal of Vibration and Acoustics, vol. 130, no. 2, Article ID 024503, 2008.

[15] C. A. Pare, Experimental evaluation of semiactive magnetorheological suspensions for passenger vehicles [M.S. thesis], Virginia Polytechnic Institute and State University, 1998.

[16] J. W. Gravatt, Magneto-rheological dampers for super-sport motorcycle applications [M.S. thesis], Virginia Polytechnic Institute and State University, 2003.

[17] S. H. Ha, S.-B. Choi, K.-S. Lee, and M.-W. Cho, "Ride quality evaluation of railway vehicle suspension system featured by magnetorheological fluid damper," Advanced Science Letters, vol. 12, no. 1, pp. 209-213, 2012.

[18] T. W. Nehl, J. A. Betts, and L. S. Mihalko, "An integrated relative velocity sensor for real-time damping applications," IEEE Transactions on Industry Applications, vol. 32, no. 4, pp. 873-881, 1996.

[19] T. W. Nehl, J. A. Betts, and L. S. Mihalko, "Vehicle suspension damper with relative velocity sensor having controlled flux path," U.S. Patent 5,251,729, 1993.

[20] D. H. Wang and T. Wang, "Principle, design and modeling of an integrated relative displacement self-sensing magnetorheological damper based on electromagnetic induction," Smart Materials and Structures, vol. 18, no. 9, Article ID 095025, 2009.

[21] D. H. Wang, X. X. Bai, and W. H. Liao, "An integrated relative displacement self-sensing magnetorheological damper: prototyping and testing," Smart Materials and Structures, vol. 19, no. 10, Article ID 105008, 2010.

[22] D.-H. Wang and X.-X. Bai, "Pareto optimization-based tradeoff between the damping force and the sensed relative displacement 
of a self-sensing magnetorheological damper," Journal of Intelligent Material Systems and Structures, vol. 22, no. 13, pp. 14511467, 2011.

[23] D.-H. Wang and X.-X. Bai, "A magnetorheological damper with an integrated self-powered displacement sensor," Smart Materials and Structures, vol. 22, no. 7, Article ID 075001, 2013.

[24] C. Chen and W.-H. Liao, "A self-sensing magnetorheological damper with power generation," Smart Materials and Structures, vol. 21, no. 2, Article ID 025014, 2012.

[25] C. Chen and W.-H. Liao, "A self-powered, self-sensing magnetorheological damper," in Proceedings of the IEEE International Conference on Mechatronics and Automation (ICMA '10), pp. 1364-1369, Xi’an, China, August 2010.

[26] K. H. Lam, Z. H. Chen, Y. Q. Ni, and H. L. W. Chan, "A magnetorheological damper capable of force and displacement sensing," Sensors and Actuators, A: Physical, vol. 158, no. 1, pp. 51-59, 2010.

[27] Z. Wang, Z. Chen, and B. F. Spencer Jr., "Self-powered and sensing control system based on MR damper: presentation and application," in Sensors and Smart Structures Technologies for Civil, Mechanical, and Aerospace Systems, vol. 7292 of Proceedings of SPIE, 729240, p. 10, International Society for Optics and Photonics, March 2009.

[28] Y.-T. Choi and N. M. Wereley, "Self-powered magnetorheological dampers," Transactions of the ASME, Journal of Vibration and Acoustics, vol. 131, no. 4, Article ID 044501, 2009.

[29] B. Sapiński, "Experimental study of a self-powered and sensing MR-damper-based vibration control system," Smart Materials and Structures, vol. 20, no. 10, Article ID 105007, 2011.

[30] G. R. Peng, W. H. Li, G. L. Hu, and G. Alici, "Design and simulation of a self-sensing MR damper," in Proceedings of the 15th International Conference on Mechatronics Technology, pp. 112-117, Melbourne, Australia, 2011. 

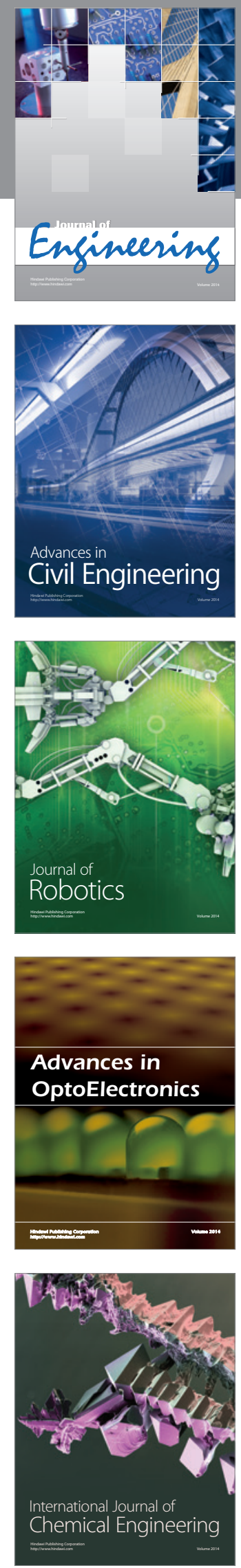

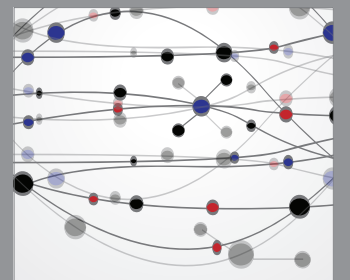

The Scientific World Journal
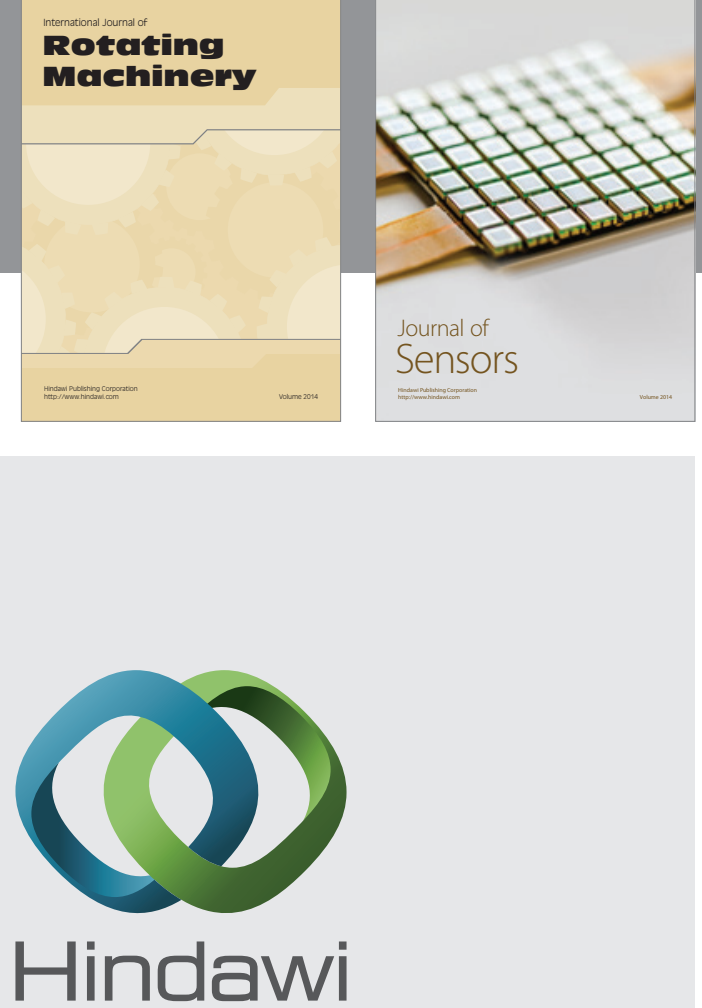

Submit your manuscripts at http://www.hindawi.com
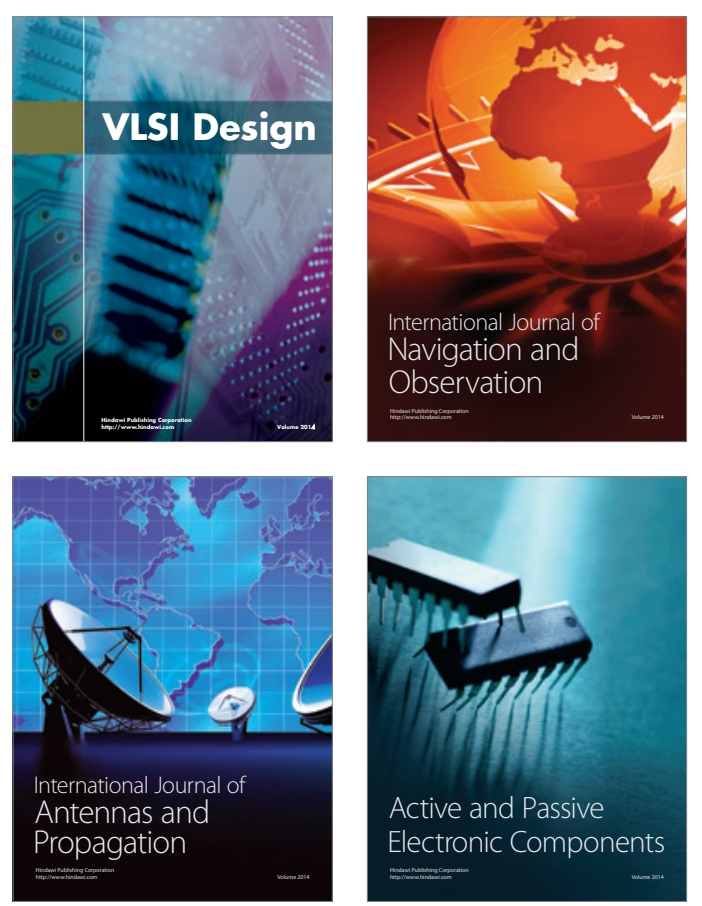
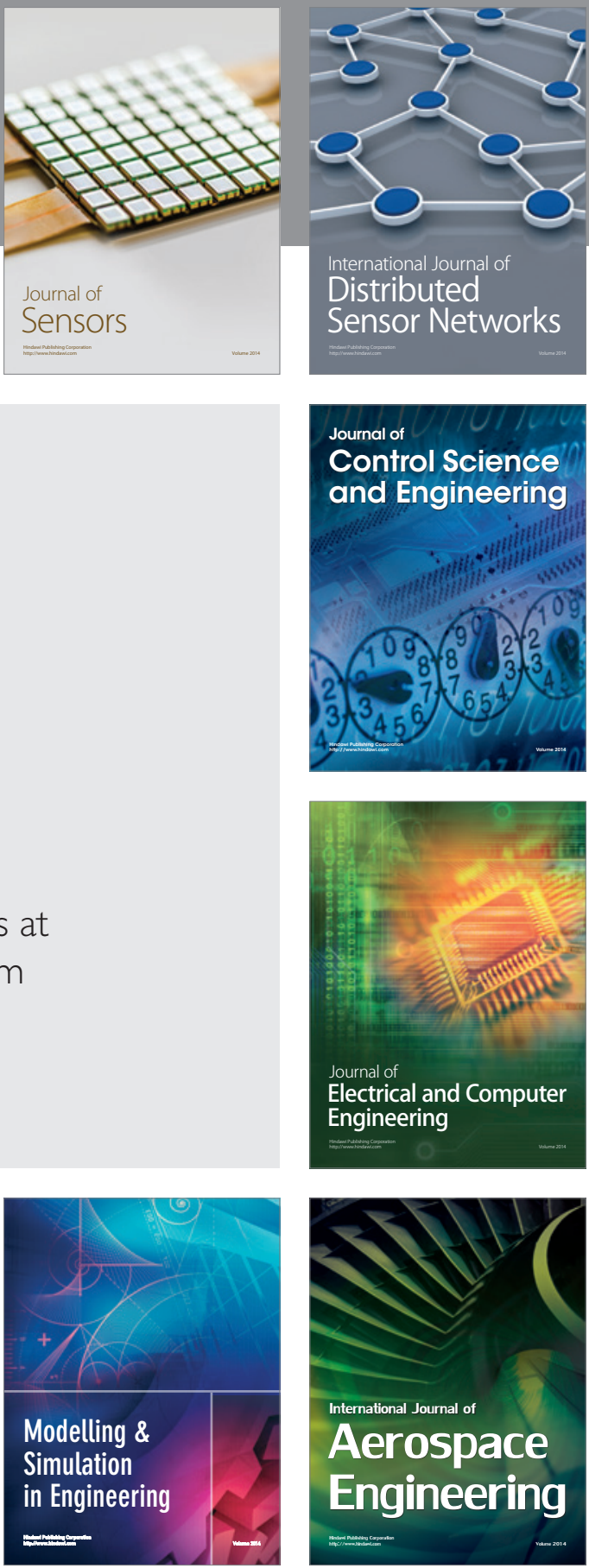

Journal of

Control Science

and Engineering
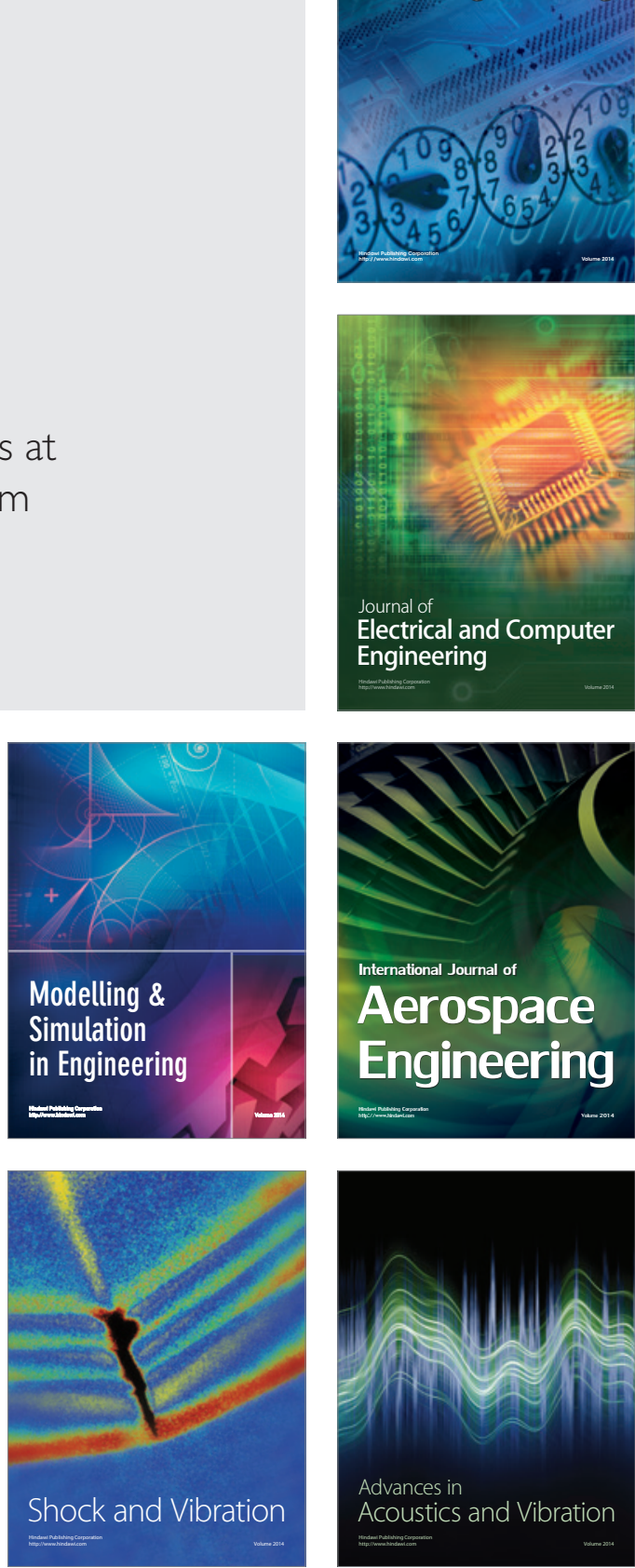